\title{
Yielding and plastic behaviour of Boom clay
}

\author{
N. Sultan ${ }^{1}$, Y.-J. Cui ${ }^{2}$, P. Delage ${ }^{2, *}$ \\ ${ }^{1}$ IFREMER, Département Géosciences Marines, France \\ ${ }^{2}$ UR Navier/CERMES, Ecole des Ponts ParisTech - Université Paris-Est, France \\ *: Corresponding author : P. Delage : delage@cermes.enpc.fr
}

\begin{abstract}
:
An underground research laboratory (URL) has been excavated in a deposit of Boom clay at a depth of $223 \mathrm{~m}$ by the SCK-CEN Belgian organisation near the city of Mol. This URL is devoted to research into nuclear waste disposal. This paper presents the results of an investigation carried out in the triaxial apparatus on specimens that were trimmed from blocks extracted during excavation sequences in the URL. In order to characterise the mechanical behaviour of the natural Boom clay and to examine the effect of initial and induced anisotropy on its constitutive behaviour, two series of triaxial tests were carried out. Special attention was devoted to the yield behaviour and the effects of stress history. Experimental results showed a clear relation between the shape of yield curves and stress history. The yield curve of the clay in its initial state was oriented along the $K_{0}$ line, illustrating the anisotropy of fabric that was generated during the soil deposition. Subsequent isotropic compression (up to $9 \mathrm{MPa}$ ) made the yield curve more and more oriented along the $p^{\prime}$ axis. Based on these experimental results, an elasto-plastic model accounting for isotropic and anisotropic hardening in $\left(p^{\prime}: q\right)$ space was developed. The initial yield curve of the soil was taken inclined with respect to the $p^{\prime}$ axis. The formulation proposed describes the change in shape, size and orientation of the yield curve, according to the stress history. Eight constitutive parameters were used to describe the anisotropic behaviour of the soil.
\end{abstract}

Keywords: plasticity; clays; anisotropy; elasticity; constitutive relations; shear strength; laboratory tests 


\section{Introduction}

An Underground Research Laboratory (URL) devoted to nuclear waste disposal research has been constructed in the deposit of a stiff clay namely Boom clay at a depth of $223 \mathrm{~m}$ by the SCK-CEN Belgian nuclear research organisation near the city of Mol. For this reason, investigation about the behaviour of Boom clay has received considerable attention. In the last two decades, research on Boom clay mainly involved the thermo-mechanical behaviour in relation to the heat generated by nuclear radiation in the soil surrounding the waste (Baldi et al., 1988, Hueckel and Baldi, 1990, De Bruyn and Thimus, 1996, Delage et al., 2000, Cui et al., 2000, Sultan et al., 2002, Cui et al., 2009, François et al., 2009 among others). In the following, attention is paid to the mechanical properties in isothermal laboratory conditions.

Many experimental studies have shown that natural fine grained soils are anisotropic and that anisotropy is related to the $K_{0}$ stress conditions associated with the process of sedimentation and the plastic straining during consolidation. Initial and induced anisotropy of natural soils have been also investigated according to the shape and the inclination of yield curves plotted in $p^{\prime}: q$ plan (Mitchell and Wong, 1973, Tavenas and Leroueil, 1979, Graham et al., 1983, Leroueil and Vaughan, 1990, Wheeler et al., 2003). From the point of view of soil fabric, the initial anisotropy is related to the preferential orientation of clay particles perpendicular to the loading direction during sedimentation and also to subsequent soil diagenesis. The mechanical response of natural clays strongly depends on changes in microstructure, in particular when the initial preferential orientation is modified by further loading paths having a different orientation with respect to the initial principal stresses (Hicher et al., 2000).

This work attempts to develop an experimental database allowing characterization of the isothermal mechanical behaviour of natural Boom clay and to examine the effect of initial and induced anisotropy on its yielding and plastic behaviour. A series of triaxial tests conducted on samples of Boom clay are presented. Some shear tests were conducted under constant confining pressures that are lower than the preconsolidation pressure previously determined. Other tests were run on overconsolidated samples that were previously consolidated under an isotropic stress of $9 \mathrm{MPa}$. Boom clay appears to present some inherent anisotropy that is progressively erased by isotropic compression.

Most existing constitutive models are derived from the critical state framework and consider the soil as being isotropic. Boehler and Sawczuk (1970) have demonstrated how complex it was to theoretically reproduce the initial and induced anisotropy of a natural soil. They stressed that the main difficulty was the experimental determination of accurate model parameters. Various authors (Dafalias, 1986, Whittle and Kavvadas, 1994 among others) have proposed to model the initial anisotropy by considering an inclined yield curve and a hardening law depending on the volumetric plastic strain, with possible rotation of the yield curve (Wheeler et al., 2003). Pietruszczak and Pande (2001) have described the inherent anisotropy within the framework of multi-laminate model. Cudny and Vermeer (2004) have shown the limitation of Pietruszczak and Pande's model and they proposed a modified multi-laminate model by considering, in addition to the strength anisotropy, the destructuration of natural clays. Pestana and Whittle (1999) extended the model of Whittle and Kavvadas (1994) with significant changes in the form of the bounding surface and hardening laws to provide a unified model for sands and clays. They checked the validity of this model in clays in Pestana et al. (2002). More recently, Wheeler et al. (2003) have demonstrated that the use of the plastic volumetric strains alone to consider the development and erasure of plastic anisotropy may lead to unrealistic predictions under certain stress paths. Wheeler et al. (2003) proposed an anisotropic elastoplastic model for soft clays by relating the 
change of the yield curve inclination to volumetric and shear plastic straining. As both volumetric and shear plastic straining are related to the stress loading path and to the stress history, the present work aims to experimentally investigate the initial and induced anisotropy of the Boom clay in terms of stress and strain components.

\section{Experimental set-up}

The mechanical behaviour of Boom clay has been studied by various authors, mostly in relation to nuclear waste disposal (Baldi et al., 1988, Bernier et al., 1997, De Bruyn and Thimus, 1996, Delage et al., 2000, Cui et al., 2000, Sultan et al., 2002, Barnichon and Volkaert, 2003, Delage et al., 2007). Boom clay is a stiff clay with a plasticity index of about $50 \%$, an initial void ratio around 0.61 and a water content comprised between 24 and $30 \%$. In this work, tests were performed on intact Boom clay specimens trimmed from block samples that were extracted during an excavation phase of the Mol URL. The initial suction of the studied samples, determined using the filter paper method, was found equal to $515 \mathrm{kPa}$.

Tests were carried out in a triaxial cell (Figure 1) designed to sustain high pressures, up to $60 \mathrm{MPa}$. A compensating system was designed in the cell to allow neutralising the pressure exerted by the confining fluid on the piston. In other words, there is no piston expulsion when the confining pressure is increased. The axial stress is applied through a hydraulic system by using a high-capacity volume-pressure controller (GDS, $60 \mathrm{MPa}$ ). The confining pressure and the back pressure are also applied by volume-pressure controllers (60 and $2 \mathrm{MPa}$ respectively). The main advantage of pressure-volume controller is their ability to monitor volume changes while applying pressures. The volume changes of the sample were monitored by using the back-pressure controller. Isotropic compressions were performed at a rate of 0.5 $\mathrm{kPa} / \mathrm{min}$, that was considered as being slow enough to ensure the complete drainage during loading. For triaxial shear tests, based on Gibson and Henkel's criteria (1954), an extremely slow shearing rate with an axial deformation of $0.003 \% / \mathrm{min}$ was applied.

\section{3. soil testing program}

\section{Preconsolidation pressure}

In order to identify the preconsolidation pressure of Boom clay, a sample was saturated under a low effective isotropic stress of $0.07 \mathrm{MPa}$ and subsequently isotropically loaded to $4 \mathrm{MPa}$. Results are presented in Figure 2, in a $e: \log \left(p^{\prime}\right)$ and $e-p^{\prime}$ plots. Figure 2 shows that the Boom clay sample has undergone some swelling during saturation. The compression curve exhibits a preconsolidation pressure $p_{c}^{\prime}$ between 0.37 (determined from semi-log plot) and $0.38 \mathrm{MPa}$ (determined from linear plot), much lower than what could be calculated from the in situ vertical stress, equal to 2.4 MPa. This shows that the soil has lost the memory of the maximum sustained load due to initial swelling during saturation. Several oedometer tests carried out on Boom clay samples have also shown a comparably low preconsolidation pressure.

The compression test of Figure 2 may also be used to determine the swelling pressure of the sample $\left(p_{G}^{\prime}\right)$ using the so-called free-swell method. In the case of isotropic loading tests, this value is slightly bigger than the $p_{\mathrm{c}}^{\prime}$ value $\left(p_{\mathrm{G}}^{\prime}=0.48 \mathrm{MPa}\right)$ 


\section{Triaxial tests}

In order to further investigate the yielding behaviour of Boom clay, two series of tests were carried out, as shown in Figure 3 and Figure 4. The first series was intended to investigate the yield locus of the clay in its initial natural state. Five triaxial samples (EBM4, EBM7, EBM8, EBM9 and EBM10) $(\phi=38 \mathrm{~mm}-\mathrm{h}=76 \mathrm{~mm})$ were saturated under a confining pressure of $1.08 \mathrm{MPa}$ and a back pressure of $1 \mathrm{MPa}$, ensuring a Skempton coefficient $B$ higher than 0.97. Upon completion of the saturation, the five samples were isotropically consolidated to five different effective mean stresses $\left(p^{\prime}=0.15,0.2 ; 0.285 ; 0.35 ; 0.365 \mathrm{MPa}\right)$, all lower than the measured preconsolidation pressure $\left(p_{c}^{\prime}=0.37 \mathrm{MPa}\right)$. Four triaxial shear tests were carried out in drained conditions $\left(p^{\prime}=0.2 ; 0.285 ; 0.35 ; 0.365 \mathrm{MPa}\right)$, and one was run in undrained conditions $\left(p^{\prime}=0.15 \mathrm{MPa}\right)$. The corresponding stress paths are indicated in Figure 3. It should be noted that test EBM8 followed a stress path defined by an inclination of $1 / 5$ whereas other tests were conducted under a constant confining pressure. The approximately vertical path followed by the undrained test (EBM9) is indicator of a fairly elastic response.

In the second series, five samples (EBM2, EBM3, EBM5, EBM6, EBM24) were saturated in the same way and isotropically consolidated under $9 \mathrm{MPa}$. Finally, they were unloaded down to five different effective mean stresses $(0.9,1,3,5$, and $7.1 \mathrm{MPa}$ respectively) corresponding to five overconsolidation ratios $\left(R_{O C}=10,9,1.8,1.25\right.$ and 3 respectively). Overconsolidated specimens were sheared in drained conditions (Figure 4). Note that for all samples tested, an isotropic volumetric swelling of around $1.5 \%$ similar to the one presented in Figure 2 was observed during the saturation process. The consequence of such isotropic swelling on the initial fabric anisotropy is obviously not negligible.

Figure 5 shows the results of the second series of tests in terms of variations of deviator stress $(q)$ and volumetric strain $\left(\varepsilon_{\mathrm{v}}\right)$ versus axial strain $\left(\varepsilon_{\mathrm{a}}\right)$. Various common behaviour features can be observed:

a) the stress-strain curves of the tests conducted at two similar overconsolidation ratios $\left(R_{O C}=9\right.$ and 10$)$ show satisfactory repeatability;

b) the soil stiffness increases with increased effective confining pressure $\sigma_{3}^{\prime}$;

c) the maximum deviator stress increases with increase of $\sigma_{3}^{\prime}$. Note that test EBM6 was prematurely interrupted at an axial deformation close to $\varepsilon_{a}=5 \%$ before reaching a maximum deviator stress. Thus for this sample close to normal consolidation $\left(R_{o c}=\right.$ $1.25)$, the critical state could not be reached. Sample EBM5 $\left(R_{o c}=1.8\right)$ reaches the critical state at $\varepsilon_{a}=8 \%$;

d) stress-strain curves of the tests at the highest overconsolidation ratios (tests EBM 2 and EBM 3, $R_{O C}=9$ and 10) exhibit a peak, followed by a softening behaviour;

c) the initial slopes of the contracting phase that includes pseudo elastic contraction are quite similar, showing in this zone $\left(\varepsilon_{\mathrm{a}}<1 \%\right)$ little effect of the increase in deviator stress;

d) a contracting-dilating behaviour is observed in the $\left(\varepsilon_{\mathrm{v}}: \varepsilon_{\mathrm{a}}\right)$ plot in the tests conducted at three high overconsolidation ratios $\left(R_{O C}=3,9\right.$ and 10). The observed dilatancy in tests at $R_{O C}=9$ and 10 is coupled with strain localisation. Dilatancy appears at $\varepsilon_{\mathrm{a}}=7 \%$ in test at $R_{O C}=3$. 


\section{Yield stress curves}

Various approaches have been considered in the literature in order to determine yield stresses. In the case of soft and structured clays sheared at constant confining pressure (see Tavenas and Leroueil, 1979), yield is often taken at the maximum deviator stress or at the peak of the stress-strain curves. In isotropic compression tests, yield is taken at the intersection of the two linear segments which best fit the curve in the $\left(\varepsilon_{v}:\right.$ In $\left.p^{\prime}\right)$ plot. In denser soils as compacted soils, no peak is generally observed and a volumetric criterion can also be used (Delage and Cui, 1995, Cui and Delage, 1996). The use of work criteria has also been used (Tavenas et al., 1979).

In this work, yield stresses were evaluated using $\left(\varepsilon_{v}-\ln p^{\prime}\right)$ plots. The synthetic presentation of experimental data is shown in Figure 6-a as proposed by Moulin (1989). It is observed that in terms of strains, the yield stress determined in the $\left(\varepsilon_{v}\right.$ In $p^{\prime}$ ) plot is in good agreement with the linear part of the curve $\varepsilon_{v}-\varepsilon_{\mathrm{a}}$. In Figure 6-b, the yield stress defined from a semi-log plot is put in a $\varepsilon_{v}-p$ ' linear plot. Interestingly, the yield stress determined previously corresponds to the change in slope in the linear plot, showing that it could be also defined using $\left(\varepsilon_{v}-p^{\prime}\right)$ plots.

Figure 7 and Figure 8 present the yield curves obtained in a $p^{\prime}-q$ plot for the two series of tests described in Figure 3 and Figure 4. A straight line corresponding to a critical state parameter $M$ equal to 0.87 taken from other results on Boom clay (Baldi et al., 1991) is also drawn. A significant difference in either the shape or the orientation of the yield curves is observed between the initial state (Figure 7) and overconsolidated states (Figure 9, after consolidation under $9 \mathrm{MPa}$ ). The yield curve in the initial state is inclined along the $K_{0}$ line whereas the yield curve of overconsolidated specimens is oriented along the $p^{\prime}$ axis.

As compared to the existing models where anisotropy is only accounted for by allowing rotation of yield curve and sometimes by changing the aspect ratio of the yield surface, experimental data presented in Figure 9 show the need to develop a new yield curve equation to account for stress history and plastic straining. It is interesting to observe in Figure 7 and Figure 8 that isotropic compression up to a stress (9 MPa) significantly higher than the initial yield stress $\left(p_{c}^{\prime}=0.37 \mathrm{MPa}\right)$ fully erases the initial anisotropy, and as a result, the yield surface becomes oriented along the isotropic axis.

\section{Constitutive modelling}

\section{Yield curve function}

In order to develop an elasto-plastic constitutive model accounting for both initial and induced anisotropy, it is necessary to find a yield function that allows satisfactory description of the hardening phenomenon experimentally observed. For this purpose, the two experimental yield curves were normalised according to the main relevant parameters in order to reach a unique normalised yield curve.

Isotropic hardening is directly depending on the void ratio which in turn depends on the maximum stress $p_{c 0}^{\prime}$ supported by the soil during its stress history. The first normalisation was hence done with respect to the maximum stress defined for Boom clay in Figure 7 by the intersection point $A$ between the $K_{0}$ line and the yield curve. In the overconsolidated state (see the yield curve of Figure 8), the maximum mean effective stress is $9 \mathrm{MPa}$. Figure 9 shows the two normalised yield curves in a $\left(q / p_{\mathrm{c} 0}^{\prime}: p^{\prime} / p_{\mathrm{c} 0}^{\prime}\right)$ plot.

Another important parameter related to microstructure changes during loading is the combined effect of shear and volumetric strains characterised by the direction of the 
stress path supported during stress history. In the initial state, this direction is defined by the $K_{0}$ parameter that corresponds to the stress conditions prevailing during the process of sedimentation. After isotropic consolidation under $9 \mathrm{MPa}$, the direction becomes horizontal due to the much higher value of the applied isotropic stress as compared to the initial state. Hence, a second normalisation was done by rotating the yield curve of the initial state clockwise. In other words, the $K_{0}$ axis was rotated in a horizontal orientation in order to fit with $p^{\prime}$ axis. This was done by applying the following transformation to the coordinates of the points corresponding to the natural state (Eq.1).

$\left[\begin{array}{c}p_{\eta}^{\prime} \\ q_{\eta}\end{array}\right]=\left[\begin{array}{cc}\cos (\alpha) & \sin (\alpha) \\ -\sin (\alpha) & \cos (\alpha)\end{array}\right]\left[\begin{array}{l}p^{\prime} \\ q\end{array}\right]$

where $\alpha=\tan ^{-1}\left(\eta_{c}\right)$ for the initial state and $\alpha=0$ for the consolidated state. $\eta_{\mathrm{c}}$ is the inclination of the $K_{0}$ line in the $p^{\prime}: q$ plot. This transformation was proposed considering the good geometric similarity observed in Figure 9 between the section of the yield curve at initial state located above the $K_{0}$ line and that of the yield curve of the consolidated soil. In Figure 10, both yield curves are represented in a $\left(q_{\eta} p_{c}^{\prime}: p_{\eta} p_{c}^{\prime}\right)$ plot.

A last normalisation in size was done by multiplying the normalised deviator stress $q_{\eta} / p_{\text {co }}^{\prime}$ by $M /\left(M-\eta_{c}\right)$. This leads to the diagram of Figure 11 where all experimental points obtained from the two series of tests are plotted together in a $\left[q_{\eta} M /\left(\left(M-\eta_{c}\right) p_{c 0}^{\prime}\right.\right.$ versus $p^{\prime} / p^{\prime}{ }_{c 0}$ ] plot. Interestingly, all the points belong to a same curve, showing the relevance of the normalisations undertaken. It has been found that the following mathematical expression (Eq. 2) is suitable to represent this normalised yield curve:

$\frac{q_{\eta}}{p_{c 0}^{\prime}} \frac{M}{M-\eta_{c}}=\frac{\left(\frac{p_{\eta}^{\prime}}{p_{c 0}^{\prime}}\right)^{2}-\frac{p_{\eta}^{\prime}}{p_{c 0}^{\prime}}}{a\left(\frac{p_{\eta}^{\prime}}{p_{c 0}^{\prime}}\right)^{2}-1}$

In the diagram of Figure 11 , this expression only depends on parameter $a$. It provides a mathematical expression $F_{1}\left(p^{\prime}, q, \eta_{\mathrm{c}}, p_{\mathrm{c} 0}^{\prime}\right)$ for the section of the yield curve of the initial state where stress inclinations $\eta$ are larger than $\eta_{\mathrm{c}}$, i.e. the section located above the $K_{0}$ line, as follows (Eq. 3):

$$
F_{1}=q_{\eta}-\left[\frac{M-\eta_{c}}{M}\right] \frac{p_{\eta}^{\prime} p_{c 0}^{\prime}\left\lfloor p_{\eta}^{\prime}-p_{c 0}^{\prime}\right\rfloor}{a p_{\eta}^{\prime 2}-p_{c 0}^{\prime 2}}=0
$$

Figure 12 shows the effects of parameter a on the shape of the yield curve. In our case, the most appropriate value is $a=0.87$.

Eq. 3 defines the yield curve as a function of the two variables $p^{\prime}{ }_{\eta}$ and $q_{\eta}$. In order to represent it in a $p^{\prime}$ - $q$ plot, a rotation must be done by using a transformation function inverse of that defined by Eq. 1.

When stress inclinations are smaller than $\eta_{c}$, i.e. below the $K_{0}$ line in the intact state, the following function $F_{2}\left(p^{\prime}, q, \eta_{\mathrm{c}}, p_{\mathrm{c} 0}^{\prime}\right)$ was adopted (Eq. 4): 


$$
F_{2}=q_{\eta}+\frac{p_{\eta}^{\prime} p_{c 0}^{\prime}\left\lfloor p_{\eta}^{\prime}-p_{c 0}^{\prime}\right\rfloor}{a p_{\eta}^{\prime 2}-p_{c 0}^{\prime 2}}=0
$$

\section{Anisotropic hardening rule}

As commented before, the shape of yield curve and its evolution due to hardening depends on the stress history and consequently on the ratio between shear and volumetric strains. The stress history can be described by the preconsolidation pressure $p_{c}^{\prime}$ and by the direction of stress path $\eta_{c}$ followed during the soil sedimentation. Parameter $p_{c}^{\prime}$ governs the size of the yield curve while parameter $\eta_{\mathrm{c}}$ defines its orientation.

An isotropic hardening law similar to that in modified Cam-clay model was adopted for parameter $p_{c}^{\prime}$, (Eq. 5). Subsequently the variation of $p_{c 0}^{\prime}$ can be evaluated using Eq. 6.

$$
\begin{aligned}
& d p_{c}^{\prime}=\frac{\left(1+e_{0}\right)}{\lambda-\kappa} p_{c}^{\prime} d \varepsilon_{v}^{p} \\
& d p_{c 0}^{\prime}=\frac{\partial p_{c 0}^{\prime}}{\partial p^{\prime}} \frac{\partial p_{c}^{\prime}}{\partial \varepsilon_{v}^{p}} d \varepsilon_{v}^{p}
\end{aligned}
$$

Eq. 7 was obtained by taking $q=0$ in function $F_{2}$ and by considering axis rotation:

$$
\frac{\partial p^{\prime}{ }_{c 0}}{\partial p^{\prime}{ }_{c}}=\frac{\cos (\alpha)[1+\sqrt{1-4(1-\tan (\alpha) \operatorname{atan}(\alpha))}]}{2(1-\tan (\alpha))}
$$

In order to define the anisotropic hardening rule that controls both the orientation and size of the yield curve, the radial increment of plastic loading $d R$ was considered as a hardening parameter (see Figure 13). This radial increment accounts for the combined effect of volumetric and shear plastic strains. This option was taken because the rearrangement of soil fabric, or the plastic strains, is thought to be mainly depending on the stress direction $\eta$. This idea is supported by the microscopic observations of Hicher et al. (2000) about the strong structural anisotropy due to large reorientation of particles in the direction perpendicular to the loading direction. The radial component of the plastic loading $d R$ is given by Eq. 8:

$$
d R=d p^{\prime} \cos \left(\tan ^{-1}\left(\frac{q}{p^{\prime}}\right)\right)+d q \sin \left(\tan ^{-1}\left(\frac{q}{p^{\prime}}\right)\right)
$$

The second hardening law directly relates the rotation of the yield surface to $d R$ and is defined geometrically in Figure 13, leading to the following expression (Eq. 9): 


$$
d \eta_{c}=\frac{d R \sin \left(\tan ^{-1}\left(\frac{q}{p^{\prime}}\right)-\tan ^{-1}\left(\eta_{c 0}\right)\right)}{p_{c 0}^{\prime}+d R \cos \left(\tan ^{-1}\left(\frac{q}{p^{\prime}}\right)-\tan ^{-1}\left(\eta_{c 0}\right)\right)}
$$

The increment of plastic volumetric strain can be calculated by applying the consistency condition, defined by $d F_{1}=0$ if $\eta>\eta_{c}$, and $d F_{2}=0$ if $\eta<\eta_{c}$ (see appendix A).

Figure 14 illustrates the change in shape and size of the yield curve according to the stress history of the soil. The yield curve (1) corresponding to the case of isotropically consolidated soil is symmetric with respect to p' axis. The yield curve (2) corresponding to a soil consolidated in oedometer (Figure 14) is oriented along the $K_{0}$ axis. The size of the zone located above the $K_{0}$ line is reduced, since the deviator $q_{\eta}$ in the $q_{\eta}: p_{\eta}^{\prime}$ plot is multiplied by $\left(M-K_{0}\right) / M$. When a sample is loaded along a stress path with a slope close to $M(M-\varepsilon$; yield curve 3$)$, the portion of the elastic zone above $M-\varepsilon$ line becomes smaller. This shape is typical of a soil loaded close to the critical state. Note that the analytical expressions of the yield curves have been determined solely based on the results of compression tests; additional extension tests are necessary to examine the possibility of any enlargement to the extension loading cases.

\section{Flow rule}

Many experimental results have shown the dependency of the plastic potential on the stress state at yield, independently of the stress path previously followed. In triaxial conditions, the stress state is completely defined by $p^{\prime}$ and $q$. In most constitutive models for saturated soils, the plastic potential only depends on the stress inclination $\eta$ (Roscoe and Burland, 1968, Wong and Mitchell, 1975, Nova and Wood, 1979). This assumption was later validated experimentally by Lanier et al. (1991). For this reason, investigations about the flow rule can be done by plotting the direction of plastic strains ratio $d=d \varepsilon_{v}^{p} / d \varepsilon_{s}^{p}$ as a function of stress ratio $\eta=q / p^{\prime}$. In the present work, plastic strains were obtained from experimental data by subtracting the elastic strain parts as presented in Figure 6-b. This is shown in Figure 15 where the experimental results of the two series of tests are presented. The following expression [Eq. 11] proposed by Lagioia et al. (1996) has been found satisfactory to relate $d=d \varepsilon_{v}^{p} / d \varepsilon_{s}^{p}$ to $\eta$.

$$
d=\frac{d \varepsilon_{v}^{p}}{d \varepsilon_{s}^{p}}=\mu\left(M_{c}-\eta\right)\left(\frac{\alpha M_{c}}{\eta}+1\right)
$$

In this expression, $M_{\mathrm{c}}$ corresponds to $\eta$ at which $d$ is equal to 0 . This condition is not necessarily corresponding to the critical state. As seen in Figure 15, the slope of the flow rule is the same for the two series of tests, independently of the stress state. However, the value of $M_{\mathrm{c}}$ is increasing with $\eta_{\mathrm{c}}$. In lack of further relevant experimental data, $M_{\mathrm{c}}$ is taken linearly dependent on $\eta_{\mathrm{c}}$ :

$$
M_{\mathrm{c}}=M+b \eta_{\mathrm{c}}
$$




\section{Comparison between experimental results and model predictions}

In total, eight parameters $(\kappa, G, \lambda, M, a, \mu, \alpha, b)$ are introduced in the model. They can be determined as follows:

$-\kappa, G, \lambda, M$ are common Cam-clay parameters and can be determined in a common fashion;

- $\mu, \alpha$ and $b$ are calculated by using the $d-\eta$ curves obtained from at least two drained triaxial tests with two soil samples isotropically consolidated before shearing at two different stresses. $\mu$ and $\alpha$ can be determined from one $d-\eta$ curve (Figure 15) and $b$ is calculated from at least two $M_{c}$ values (equation 12 and Figure 15);

- parameter $a$ that governs the shape of the yield curve is derived from the yield point of a shear test on a natural sample confined under an initial isotropic stress lower than the in situ mean effective stress (Figure 7).

In order to validate the model, two tests (EBM5 and EBM24) presented in Figure 5 and Figure 6 were simulated. Parameters used in the simulation are $\mu=1.08$, $\alpha=0.001, b=0.59, M=0.87, a=0.87, \lambda=0.178, \kappa=0.046$ and $G=95 \mathrm{MPa}$. The two experimental tests, EBM5 and EBM24, were excluded from the parameter determination process. The $M$ value was taken from Baldi et al. (1991) and parameter a was derived from the initial yield curve presented in Figure 7.

Figure 16 shows, in a normalised diagram, the hardening of the soil, from an initial anisotropic state until a final isotropically consolidated state under $9 \mathrm{MPa}$. Due to the isotropic consolidation, the axis of yield surface progressively rotates from the initial $K_{0}$ position to horizontal position. At initial and final states, a good agreement is obtained between experimental and predicted yield curves, showing that the hardening laws work correctly (Figure 16). Comparison between the predicted and experimental stressstrain curves of EBM5 and EBM24 tests also lead to a satisfactory conclusion (Figure 17 and Figure 18).

To further validate the model, the experimental results obtained by Graham and Houlsby (1983) on Winnipeg plastic clay were used for simulation. The tests were performed on samples extracted at various depths, resulting in four different preconsolidation pressures and four different yield curves. The shape parameter a was determined using data from the smallest yield curve $\left(\sigma_{\mathrm{v}}^{\prime}=190 \mathrm{kPa}, a=0.92\right)$. The remaining parameters were given in Graham and Houlsby (1983): $\kappa=0.078, \lambda=0.305$, $M=0.67$.

Starting from the smallest yield surface, the three others were simulated by following a $K_{0}$ stress path. The good agreement between the predicted and observed yield curves (Figure 19) confirms the validity of the model in terms of isotropic hardening law.

\section{Conclusions}

High-capacity triaxial tests were carried out on Boom clay specimens trimmed from blocks extracted at a depth of 223 in the Underground Research Laboratory of SCKCEN in Mol (Belgium) to study its yielding and plastic behaviour. Based on the experimental data obtained on soil samples in their initial state and after having been consolidated under high pressure (9 MPa), a constitutive model accounting for both initial and induced anisotropy was developed. The following concluding remarks can be drawn.

Firstly, due to the swelling behaviour of Boom clay, initial wetting under low stress significantly decreased the value of preconsolidation pressure $p_{c}^{\prime}$. It suspected that swelling soils may loose their memory when saturated under low stresses, in 
accordance with the statements made by Gens and Alonso (1992) and Cui et al. (2002).

Secondly, experimental data showed a clear relation between the yield properties and the previous stress history. The yield curve of samples taken in their initial state was oriented along the $K_{0}$ line, illustrating the anisotropy of the fabric that was created during soil deposition and subsequent diagenesis. Note that swelling did not seem to affect the structural anisotropy significantly.

Isotropic loading up to $9 \mathrm{MPa}$ rotated the yield curve in the $p^{\prime}-q$ plot, giving rise to an isotropic yield curve, in agreement with observations made by Hicher et al., (2000). In addition, the direction of the plastic strain vectors evidenced a non associated flow rule.

The model developed is defined by eight parameters. The formulation proposed for the yield curve account for the changes in shape that occur during hardening. Some simulations performed showed satisfactory responses. Being developed in the triaxial state of stresses, the investigation conducted here is certainly not sufficient to fully characterise and model the anisotropic elasto-plastic behaviour of natural clay (see for instance Pestana et al., 2002 and Baker and Desai, 1984). However, it is believed that the experimental data and formulations obtained in this work will help in a better understanding of the mechanical behaviour of Boom clay.

\section{References}

Baker, R. \& Desai, C. S. (1984). Induced anisotropy during plastic straining. International Journal for Numerical and Analytical Methods in Geomechanics 8, 167-185.

Baldi, G., Hueckel, T. \& Pellegrini, R. (1988). Thermal volume changes of the mineral water-system in low-porosity clay soils. Canadian Geotechnical Journal 25, No. 4, 807-825.

Baldi, G., Hueckel, T., Peano, A. \& Pellegrini, R. (1991). Developments in modelling of thermohydro-geomechanical behaviour of boom clay and clay-based buffer materials (vol. 2). Commission of the European Communities, Nuclear Science and Technology EUR 13365/2.

Barnichon, J. D. \& Volckaert, G. (2003). Observations and predictions of hydromechanical coupling effects in the boom clay, Mol underground research laboratory, belgium. Hydrogeology Journal 11, No. 1, 193-202.

Bernier, F., Volckaert, G., Alonso, E. \& Villar, M. (1997). Suction-controlled experiments on boom clay. International Workshop on Hydro-ThermoMechanics of Engineered Clay Barriers and Geological Barriers. Montreal, Canada.

Boehler, J. P. \& Sawczuk, A. (1970). Equilibre limite des sols anisotropes. J. Mécanique 9, 5-33.

Cudny, M. \& Vermeer, P. A. (2004). On the modelling of anisotropy and destructuration of soft clays within the multi-laminate framework. Computers and Geotechnics 31, No. 1, 1-22.

Cui, Y. J. \& Delage, P. (1996). Yielding and plastic behaviour of an unsaturated compacted silt. Géotechnique 46, No. 2, 291-311.

Cui, Y. J., Sultan, N. \& Delage, P. (2000). A thermomechanical model for saturated clays. Canadian Geotechnical Journal 37, No. 3, 607-620.

Cui, Y.J., Yahia-Aissa, M., Delage, P. (2002). A model for the volume change behaviour of heavily compacted swelling clays. Engineering Geology 64, No 23, 233-250. 
Cui, Y.J., Le, T.T., Tang, A.M., Delage, P., Li, X.L. (2009). Investigating the time dependent behaviour of Boom clay under thermo-mechanical loading. Géotechnique, 59 No 4, 319-329.

Dafalias, Y. F. (1986). An anisotropic critical state soil plasticity model. Mechanics Research Communications 13, No. 6, 341-347.

De Bruyn, D. \& Thimus, J.F. (1996). The influence of temperature on mechanical characteristics of Boom clay: the results of an initial laboratory programme. Engineering Geology 41, Nos. 1 - 4, 117 - 126.

Delage, P., Cui, Y. J. (1995). Comportement élastoplastique d'un limon compacté. Comptes-Rendus de l'Académie des Sciences, t. 320, série Ilb, 317-324.

Delage, P., Sultan, N. \& Cui, Y. J. (2000). On the thermal consolidation of boom clay. Canadian Geotechnical Journal 37, No. 2, 343-354.

Delage, P., Le, T.T., Tang, A.M., Cui, Y.J., Li, X.L. (2007). Suction and in-situ stresses of deep Boom clay samples. Géotechnique 57 (1), 239-244.

François, B., Laloui, L. \& Laurent, C. (2009). Thermo-hydro-mechanical simulation of Atlas in situ large scale test in boom clay. Computers and Geotechnics 36, No. 4, 626-640.

Gens, A. \& Alonso, E. E. (1992). A framework for the behavior of unsaturated expansive clays. Canadian Geotechnical Journal 29, No. 6, 1013-1032.

Gibson, R. E. \& Henkel, D. J. (1954). Influence of duration of tests at constant rate of strain on measured 'drained' strength. Géotechnique 4, No. 1, 6-15.

Graham, J. \& Houlsby, G. T. (1983). Anisotropic elasticity of a natural clay. Géotechnique 33, No. 2, 165-180.

Graham, J., Noonan, M. L. \& Lew, K. V. (1983). Yield states and stress-strain relationships in a natural plastic clay. Canadian Geotechnical Journal 20, No. 3, 502-516.

Hicher, P. Y., Wahyudi, H. \& Tessier, D. (2000). Microstructural analysis of inherent and induced anisotropy in clay. Mechanics of Cohesive-Frictional Materials 5, No. 5, 341-371.

Hueckel, T. \& Baldi, G. (1990). Thermoplasticity of saturated clays - experimental constitutive study. Journal of Geotechnical Engineering-ASCE 116, No. 12, 1778-1796.

Lagioia, R., Puzrin, A. M. \& Potts, D. M. (1996). A new versatile expression for yield and plastic potential surfaces. Computers and Geotechnics 19, No. 3, 171-191.

Lanier, J., Di Prisco, C. \& Nova, R. (1991). Etude expérimentale et analyse théorique de l'anisotropie induite du sable d'Hostun. Revue Française de Géotechnique 57, 59-74.

Leroueil, S. \& Vaughan, P. R. (1990). The general and congruent effects of structure in natural soils and weak rocks. Géotechnique 40, No. 3, 467-488.

Mitchell, R. J. \& Wong, K. K. (1973). The generalized failure of an Ottawa Valley Champlain sea clay. Canadian Geotechnical Journal 10, 607-616.

Moulin, G. (1989). Caractérisation de l'état limite de l'argile de Pornic. Canadian Geotechnical Journal 31, No. 4, 705-717.

Nova, R. \& Wood, D. M. (1979). Constitutive model for sand in triaxial compression. International Journal for Numerical and Analytical Methods in Geomechanics 3, No. 3, 255-278.

Pestana, J. M. \& Whittle, A. J. (1999). Formulation of a unified constitutive model for clays and sands. International Journal for Numerical and Analytical Methods in Geomechanics 23, No. 12, 1215-1243.

Pestana, J. M., Whittle, A. J. \& Gens, A. (2002). Evaluation of a constitutive model for clays and sands: Part ii - clay behaviour. International Journal for Numerical and Analytical Methods in Geomechanics 26, No. 11, 1123-1146. 
Pietruszczak, S. \& Pande, G. N. (2001). Description of soil anisotropy based on multilaminate framework. International Journal for Numerical and Analytical Methods in Geomechanics 25, No. 2, 197-206.

Roscoe, K. H. \& Burland, J. B. (1968). On the generalized stress-strain behaviour of "wet" clay. Symp. on Eng. Plasticity, Cambridge, 535-610.

Sultan, N., Delage, P. \& Cui, Y. J. (2002). Temperature effects on the volume change behaviour of boom clay. Engineering Geology 64, No. 2-3, 135-145.

Tavenas, F., Desrosiers, J. P., Leroueil, S., Larochelle, P. \& Roy, M. (1979). Use of strain-energy as a yield and creep criterion for lightly overconsolidated clays. Géotechnique 29, No. 3, 285-303.

Tavenas, F. \& Leroueil, F. (1979). Les concepts d'état limite et d'état critique et leurs applications pratiques à l'étude des argiles. Rev. Française de Géotechnique $\mathbf{6}$, 27-49.

Wheeler, S. J., Naatanen, A., Karstunen, M. \& Lojander, M. (2003). An anisotropic elastoplastic model for soft clays. Canadian Geotechnical Journal 40, No. 2, 403-418.

Whittle, A. J. \& Kavvadas, M. J. (1994). Formulation of MIT-E3 constitutive model for overconsolidated clays. Journal of Geotechnical Engineering-ASCE 120, No. 1, 173-198.

Wong, P. K. K. \& Mitchell, R. J. (1975). Yielding and plastic-flow of sensitive cemented clay. Géotechnique 25, No. 4, 763-782.

\section{Appendix A : consistency conditions and hardening laws}

The two consistency conditions $d F_{1}=0$ and $d F_{2}=0$ are given by equation A-1:

$$
\begin{aligned}
d F_{1-2}= & {\left[\frac{\partial F_{1-2}}{\partial p_{\eta}^{\prime}} \frac{\partial p_{\eta}^{\prime}}{\partial p^{\prime}}+\frac{\partial F_{1-2}}{\partial q_{\eta}} \frac{\partial q_{\eta}}{\partial p^{\prime}}\right] d p^{\prime}+\left[\frac{\partial F_{1-2}}{\partial p_{\eta}^{\prime}} \frac{\partial p_{\eta}^{\prime}}{\partial q}+\frac{\partial F_{1-2}}{\partial q_{\eta}} \frac{\partial q_{\eta}}{\partial q}\right] d q+} \\
& {\left[\frac{\partial F_{1-2}}{\partial p_{\eta}^{\prime}} \frac{\partial p_{\eta}^{\prime}}{\partial \eta_{c}}+\frac{\partial F_{1-2}}{\partial q_{\eta}} \frac{\partial q_{\eta}}{\partial \eta_{c}}+\frac{\partial F_{1-2}}{\partial \eta_{c}}\right] d \eta_{c}+\left[\frac{\partial F_{1-2}}{\partial p_{c 0}^{\prime}}\right] d p_{c 0}^{\prime}=0 }
\end{aligned}
$$

with

$$
d p_{c 0}^{\prime}=\frac{\partial p_{c 0}^{\prime}}{\partial p_{c}^{\prime}} \frac{\partial p_{c}^{\prime}}{\partial \varepsilon_{v}^{p}} d \varepsilon_{v}^{p}
$$

Therefore $d \varepsilon_{v}^{p}$ can be calculated using the following expression:

$$
d \varepsilon_{v}^{p}=\frac{\left[\frac{\partial F_{1-2}}{\partial p_{\eta}^{\prime}} \frac{\partial p_{\eta}^{\prime}}{\partial p^{\prime}}+\frac{\partial F_{1-2}}{\partial q_{\eta}} \frac{\partial q_{\eta}}{\partial p^{\prime}}\right] d p^{\prime}+\left[\frac{\partial F_{1-2}}{\partial p_{\eta}^{\prime}} \frac{\partial p_{\eta}^{\prime}}{\partial q}+\frac{\partial F_{1-2}}{\partial q_{\eta}} \frac{\partial q_{\eta}}{\partial q}\right] d q+\left[\frac{\partial F_{1-2}}{\partial p_{\eta}^{\prime}} \frac{\partial_{\eta}^{\prime}}{\partial \eta_{c}}+\frac{\partial F_{1-2}}{\partial q_{\eta}} \frac{\partial q_{\eta}}{\partial \eta_{c}}+\frac{\partial F_{1-2}}{\partial \eta_{c}}\right] d \eta_{c}}{-\left[\frac{\partial F_{1-2}}{\partial p_{c 0}^{\prime}}\right] \frac{\partial p_{c 0}^{\prime}}{\partial p_{c}^{\prime}} \frac{\partial p_{c}^{\prime}}{\partial \varepsilon_{v}^{p}}}
$$

where the partial differential terms are given by the following two tables: 


\begin{tabular}{|c|c|c|}
\hline$\frac{\partial . \rightarrow}{\partial . \downarrow}$ & $\mathrm{F}_{1}$ & $\mathrm{~F}_{2}$ \\
\hline $\mathrm{p}_{\eta}^{\prime}$ & $-\frac{M-\eta_{c}}{M}\left[\frac{a\left(p_{c 0}^{\prime} p_{\eta}^{\prime}\right)^{2}+p_{c 0}^{\prime 3}\left(p_{c 0}^{\prime}-2 p_{\eta}^{\prime}\right)}{\left(a p_{\eta}^{\prime 2}-p_{c 0}^{\prime 2}\right)}\right.$ & {$\left[\frac{a\left(p_{c 0}^{\prime} p_{{ }_{\eta}}^{\prime}\right)^{2}+p_{c 0}^{\prime 3}\left(p_{c 0}^{\prime}-2 p_{\eta}^{\prime}\right)}{\left(a p^{\prime 2}{ }_{\eta}-p_{c 0}^{\prime 2}\right)}\right]$} \\
\hline $\mathrm{q}_{\eta}$ & 1 & 1 \\
\hline $\mathrm{p}_{\mathrm{c} 0}^{\prime}$ & $-\frac{M-\eta_{c}}{M} p_{\eta}^{\prime 2}\left[\frac{a p_{\eta}^{\prime 2}-2 a p_{c 0}^{\prime} p_{\eta}^{\prime}+p_{c 0}^{\prime 2}}{\left(a p_{\eta}^{\prime 2}-p_{c 0}^{\prime 2}\right)^{2}}\right]$ & $p_{\eta}^{\prime 2}\left[\frac{a p_{\eta}^{\prime 2}-2 a p_{c 0}^{\prime} p_{\eta}^{\prime}+p_{c 0}^{\prime 2}}{\left(a p_{\eta}^{\prime 2}-p_{c 0}^{\prime 2}\right)^{2}}\right]$ \\
\hline$\overline{\eta_{\mathrm{c}}}$ & $\frac{1}{M} \frac{p_{\eta}^{\prime} p_{c 0}^{\prime}\left[p_{\eta}^{\prime}-p_{c 0}^{\prime}\right]}{a p_{\eta}^{\prime 2}-p_{c 0}^{\prime 2}}$ & 0 \\
\hline
\end{tabular}

Table A-1: Differential terms associated to F1 and F2 used in equation A-3.

\begin{tabular}{|c|c|c|}
\hline$\frac{\partial . \rightarrow}{\partial \cdot \downarrow}$ & $\mathrm{p}_{\eta}^{\prime}$ & $\mathrm{q}_{\eta}$ \\
\hline $\mathrm{p}^{\prime}$ & $\cos (\alpha)$ & $-\sin (\alpha)$ \\
\hline $\mathrm{q}$ & $\sin (\alpha)$ & $\cos (\alpha)$ \\
\hline$\eta_{\mathrm{c}}$ & $\frac{q_{\eta}}{1+\eta_{c}^{2}}$ & $-\frac{p_{\eta}^{\prime}}{1+\eta_{c}^{2}}$ \\
\hline
\end{tabular}

Table A-2: Differential terms associated to $p_{\eta}^{\prime}$ and $q_{\eta}$ used in equation A-3. 
Figure 1. High pressure triaxial device (up to $60 \mathrm{MPa}$ ).

Figure 2. Isotropic compression with previous hydration under low stress in a) a semilog plot and b) linear plot.

Figure 3. First series of triaxial tests (initial state): effective stress paths.

Figure 4. Second series of triaxial tests (samples previously isotropically consolidated to $9 \mathrm{MPa}$ ): effective stress paths.

Figure 5. Stress-strain curves, samples isotropically consolidated to $9 \mathrm{MPa}$ a) $q-\varepsilon_{\mathrm{a}}-\mathrm{b}$ ) $\varepsilon_{\mathrm{a}}-\varepsilon_{\mathrm{v}}$

Figure 6. a) Synthetic presentation of the EBM5 triaxial test and b) yield stress determined from a semi log plot projected in a $\varepsilon_{v}-p$ ' linear plot.

Figure 7. Yield curve of Boom clay (initial state). At this stage, the yield curve is obtained by a spline smoothing of the data.

Figure 8. Yield curve of Boom clay (samples isotropically consolidated to $9 \mathrm{MPa}$ ). At this stage, the yield curve is obtained by a spline smoothing of the data.

Figure 9. Normalised yield curves with respect to the maximum preconsolidation pressure $p_{c O}^{\prime}$ (initial state and isotropically consolidated to $9 \mathrm{MPa}$ ).

Figure 10. Normalised yield curves with respect to $\eta_{c}$ (initial state and isotropically consolidated to $9 \mathrm{MPa}$ ).

Figure 11. Normalised yield curves with respect to $M^{*}$ (initial state and isotropically consolidated to $9 \mathrm{MPa}$ ).

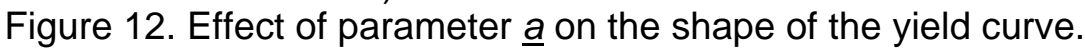

Figure 13. Anisotropic hardening of the yield curve as a function of the plastic loading stress dR.

Figure 14. Change in size and shape of the yield curve according to the stress history. Three illustrating examples for three different initial stress paths.

Figure 15. Flow rule for natural and isotropically consolidated Boom clay.

Figure 16. Hardening phenomenon: from an initial anisotropic soil to an isotropic soil, showing the erasure of the fabric anisotropy.

Figure 17. Predicted and observed stress-strain curves (sample EBM5).

Figure 18. Predicted and observed stress-strain curves (sample EBM24).

Figure 19. Predicted and observed yield curves determined for 4 different preconsolidation pressures (experimental data from Graham and Houlsby, 1983). 


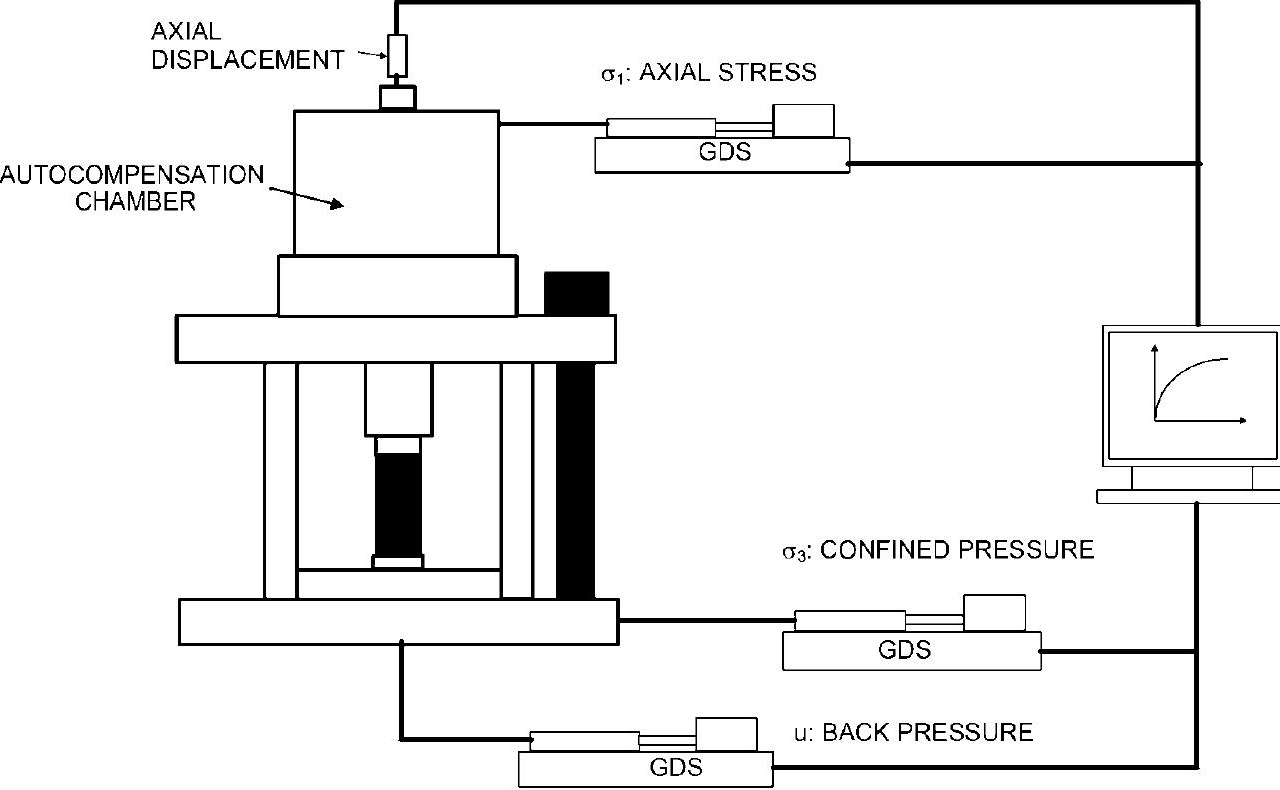


a)
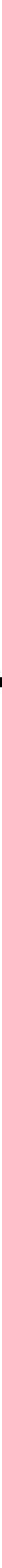


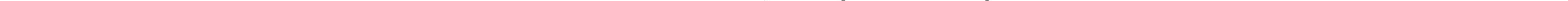



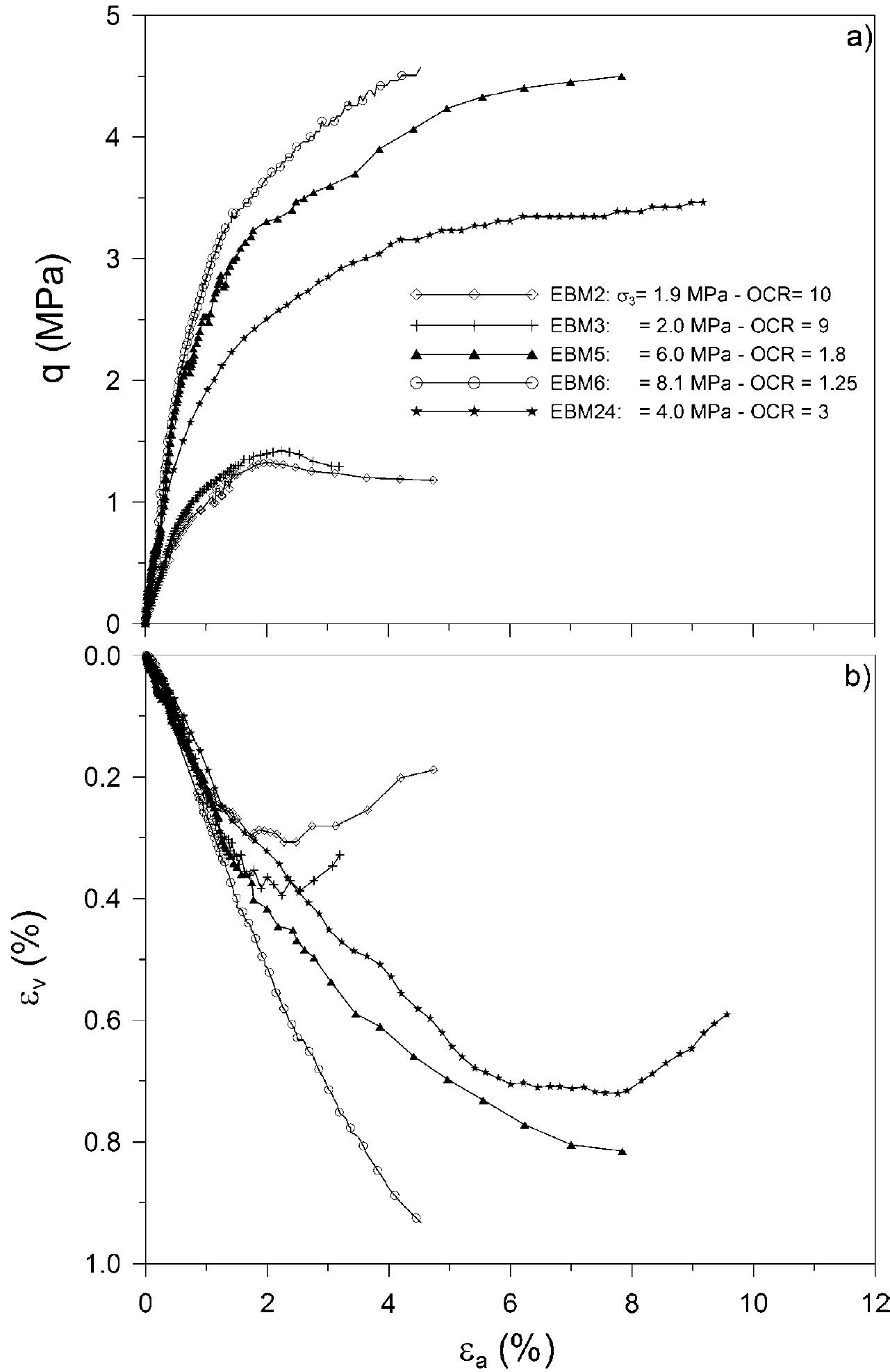

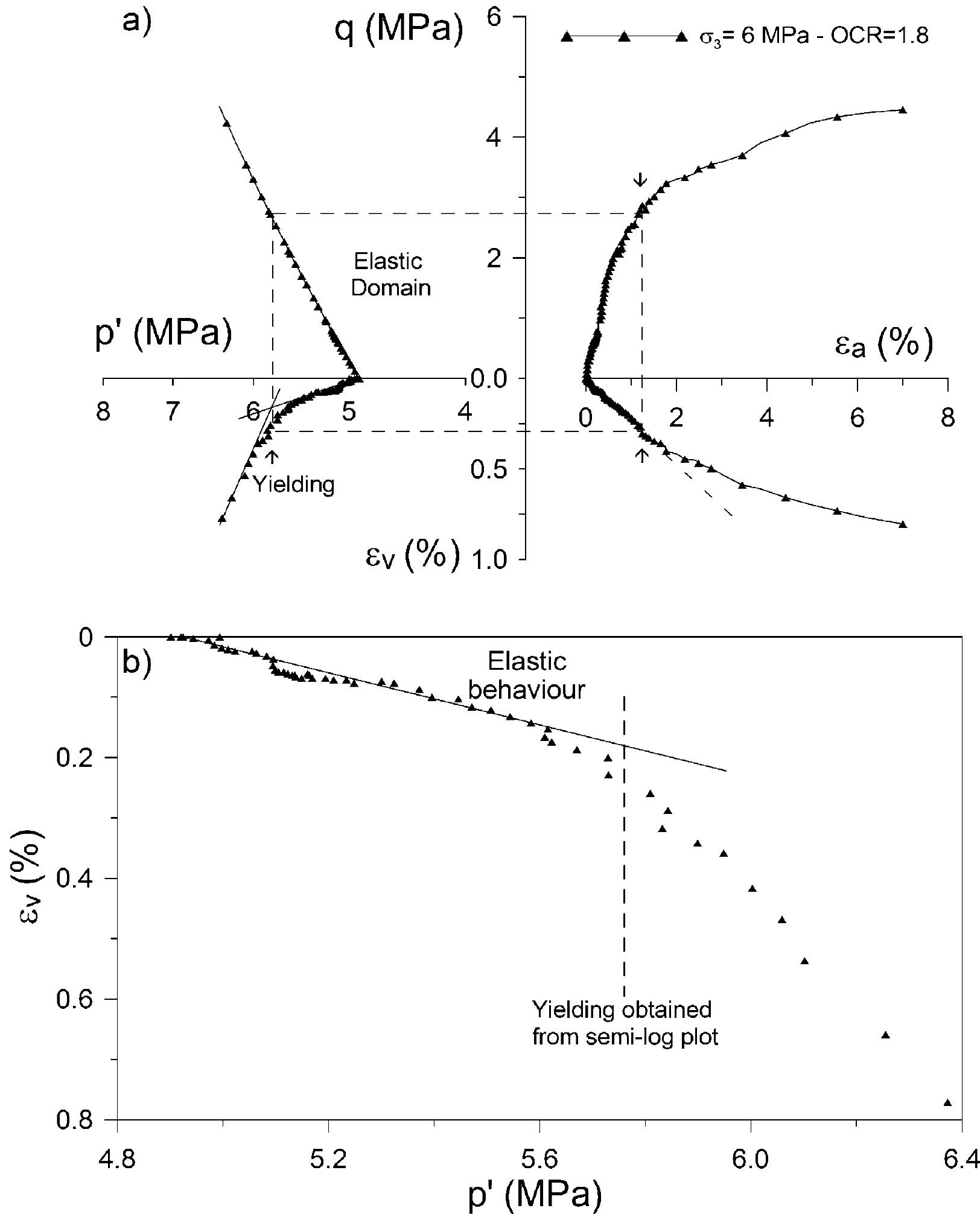


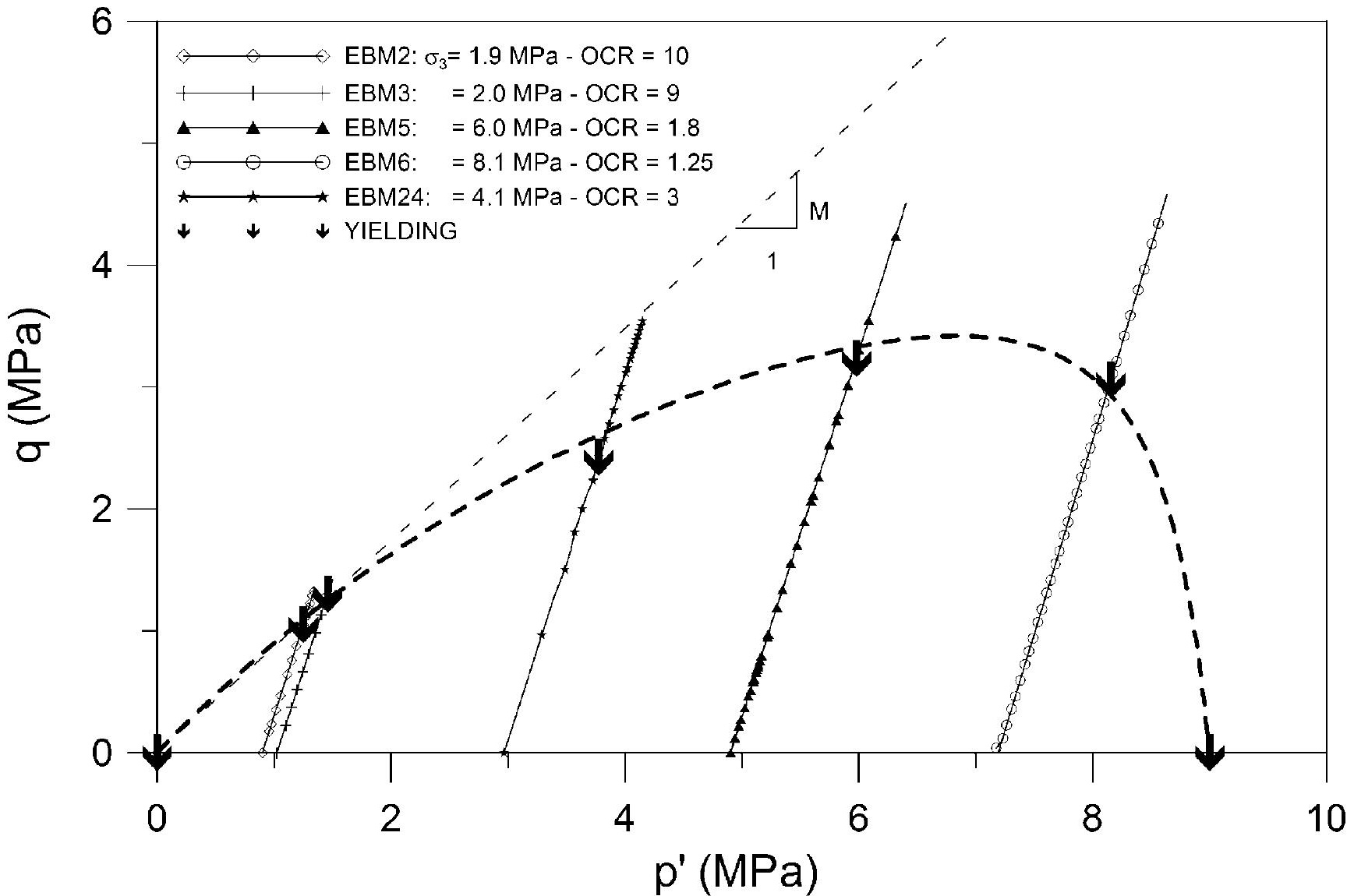




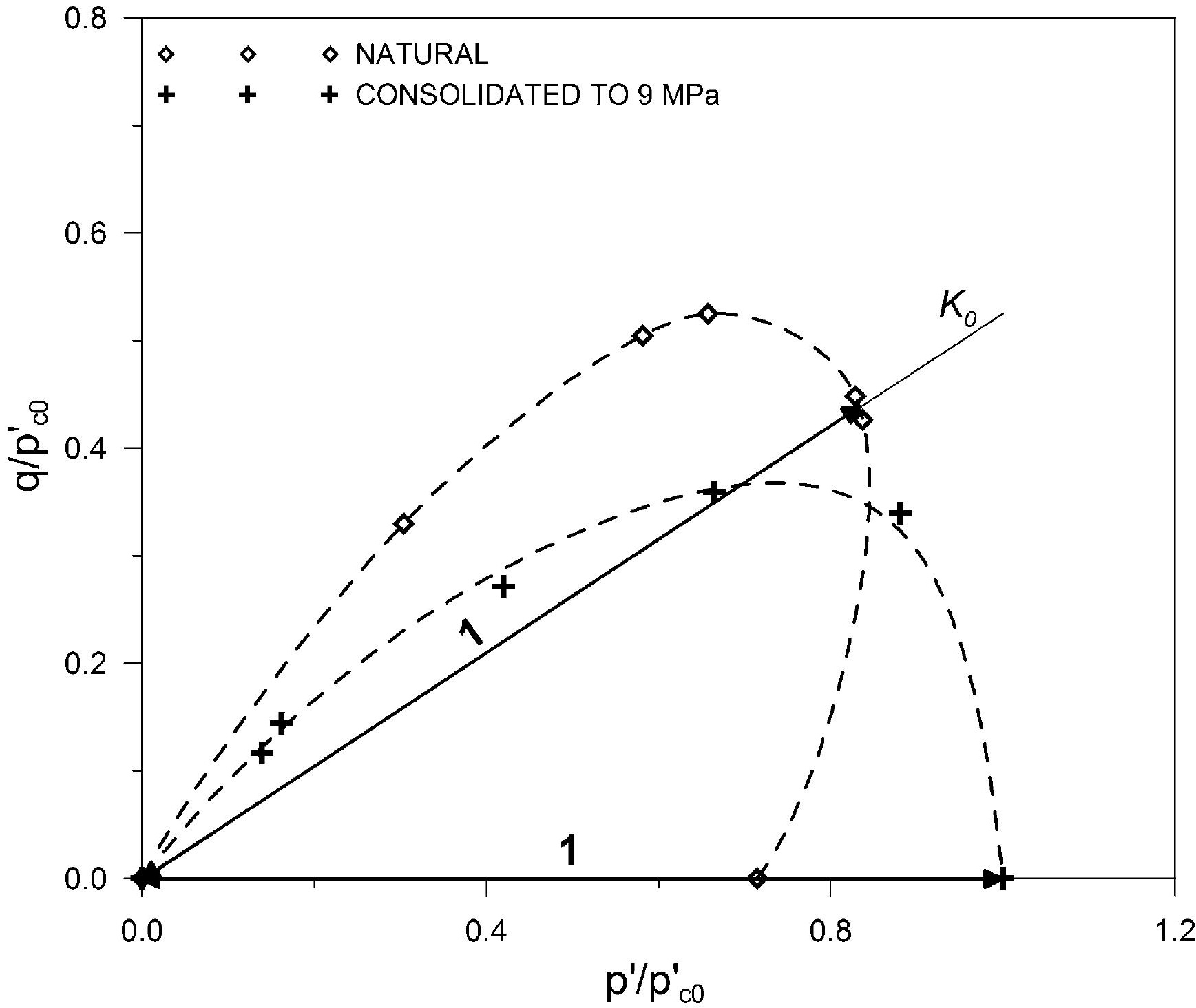




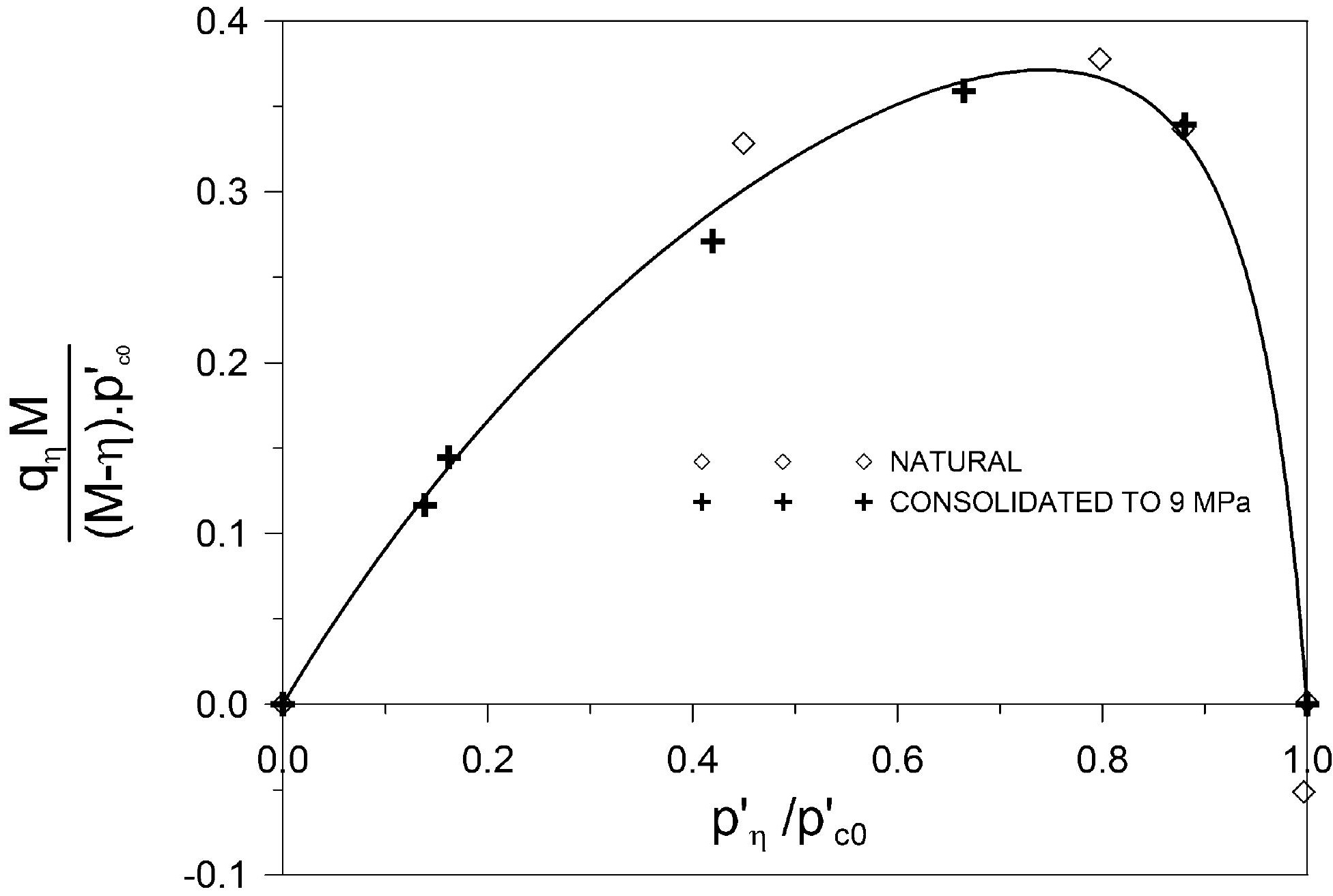




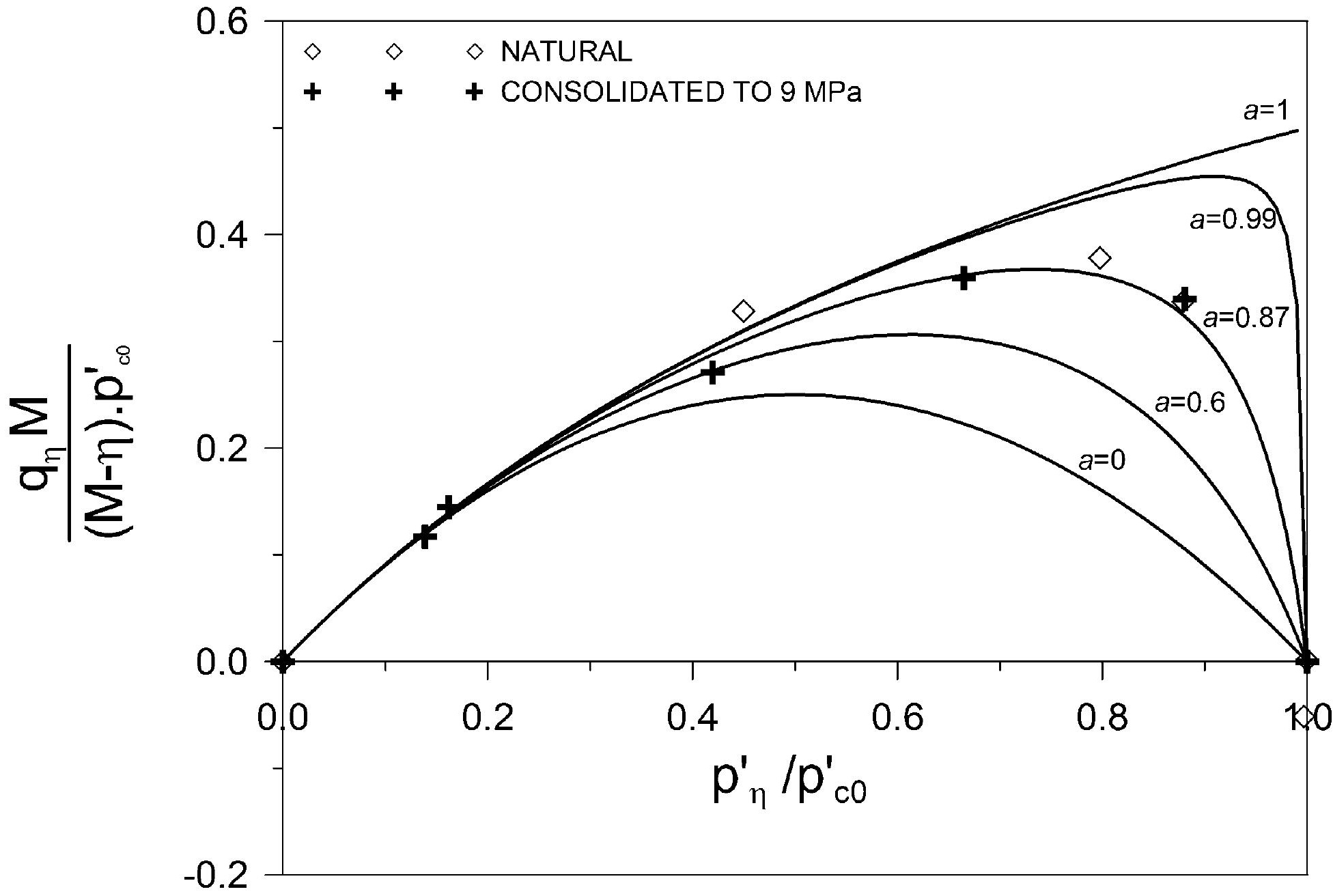




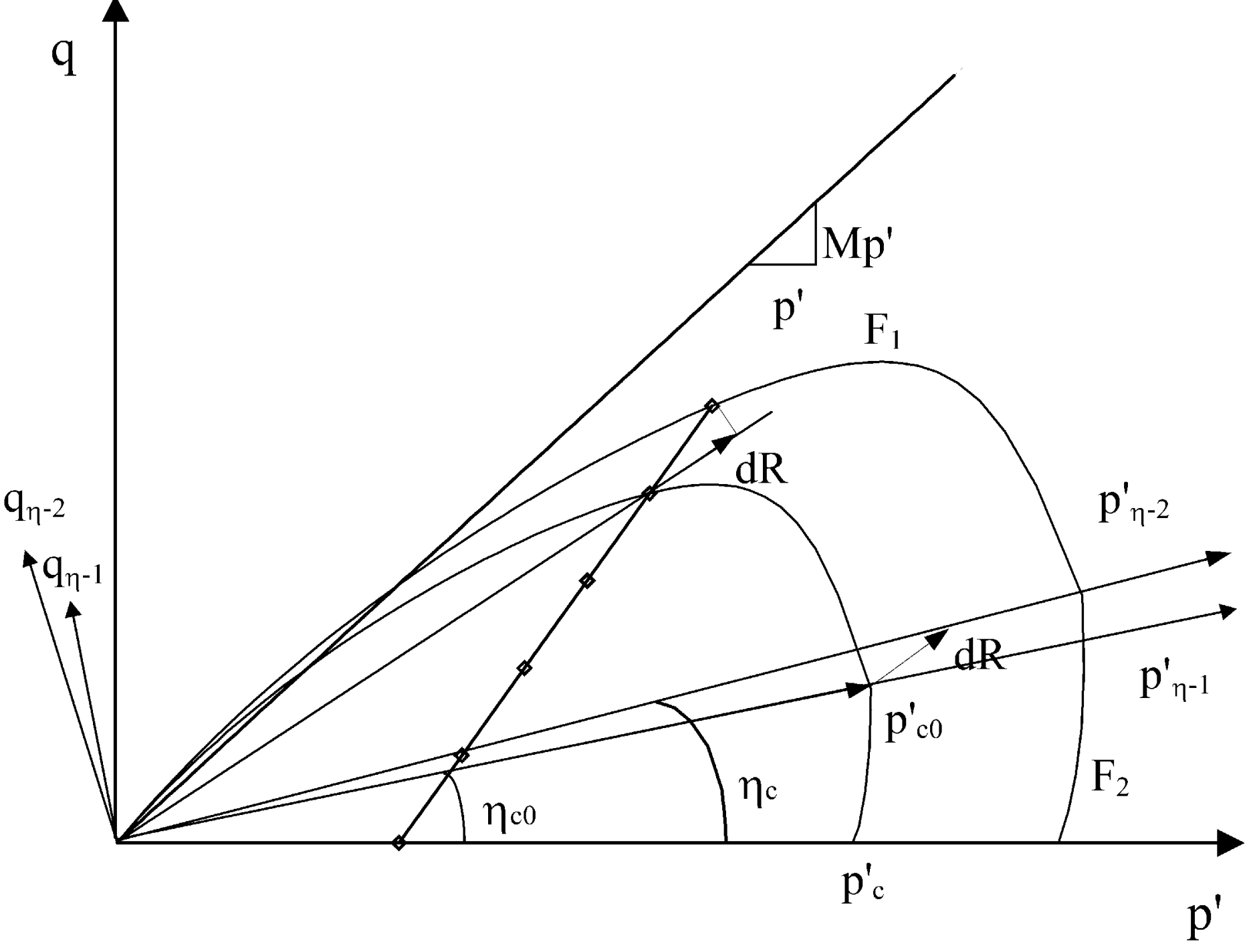




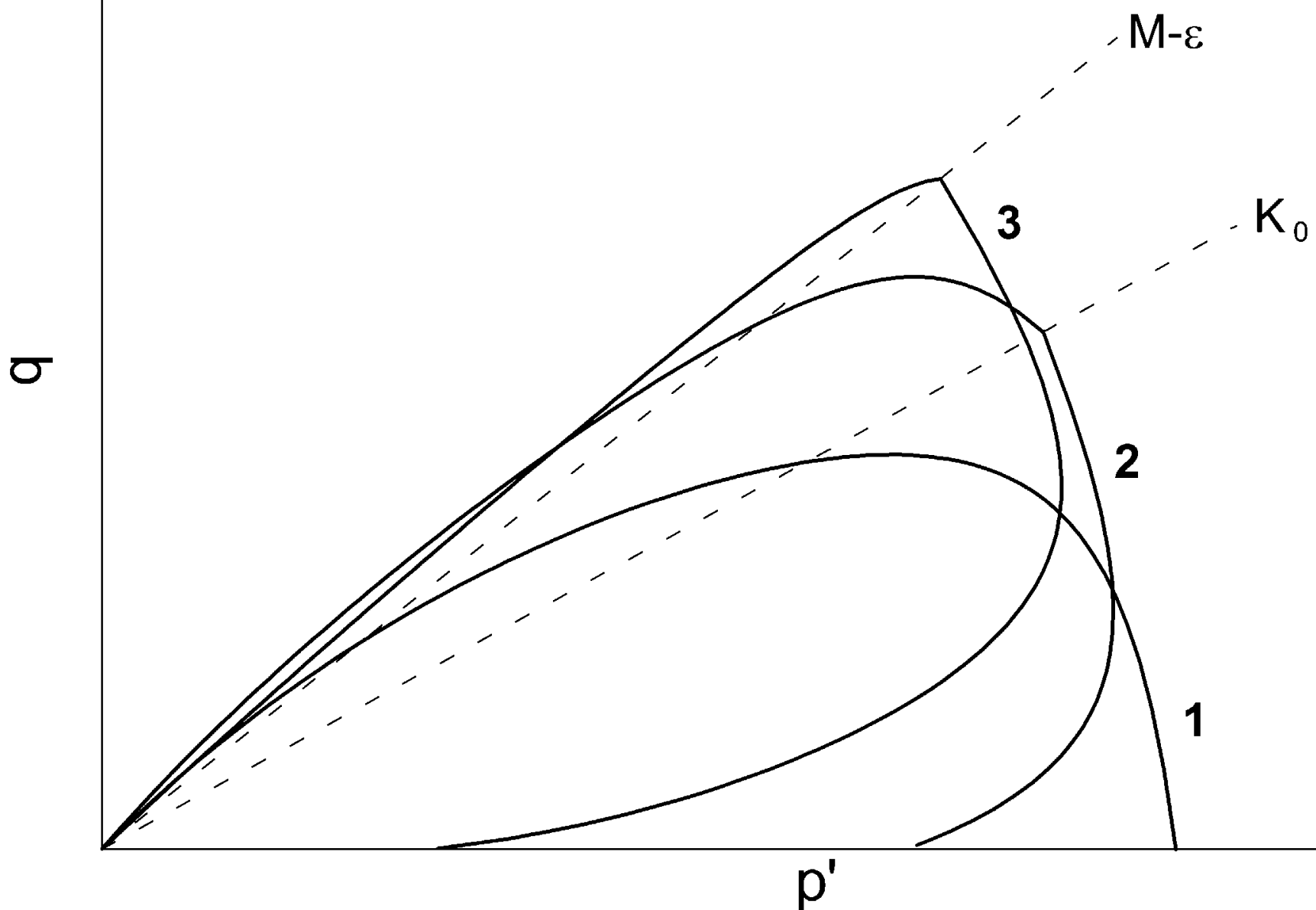




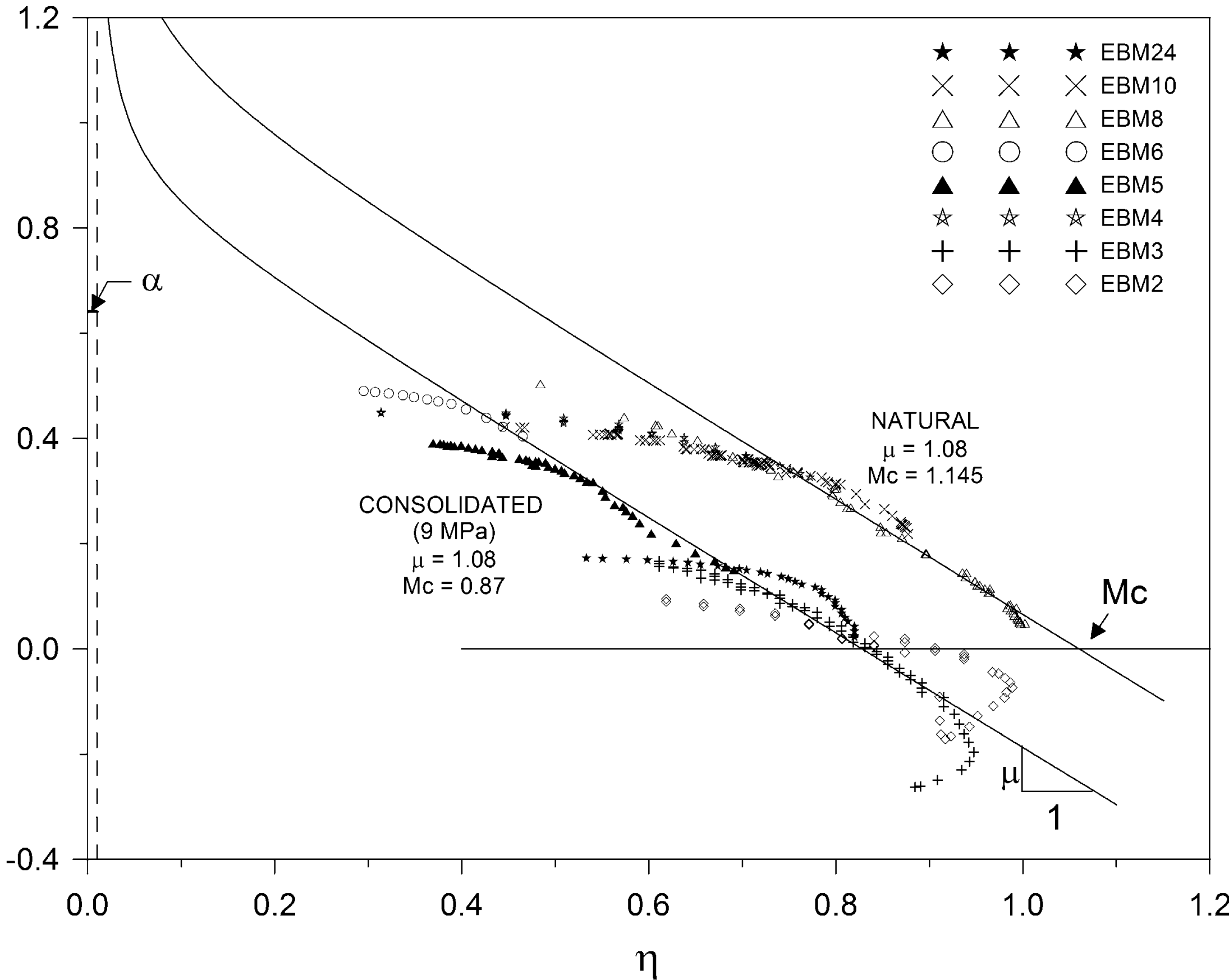




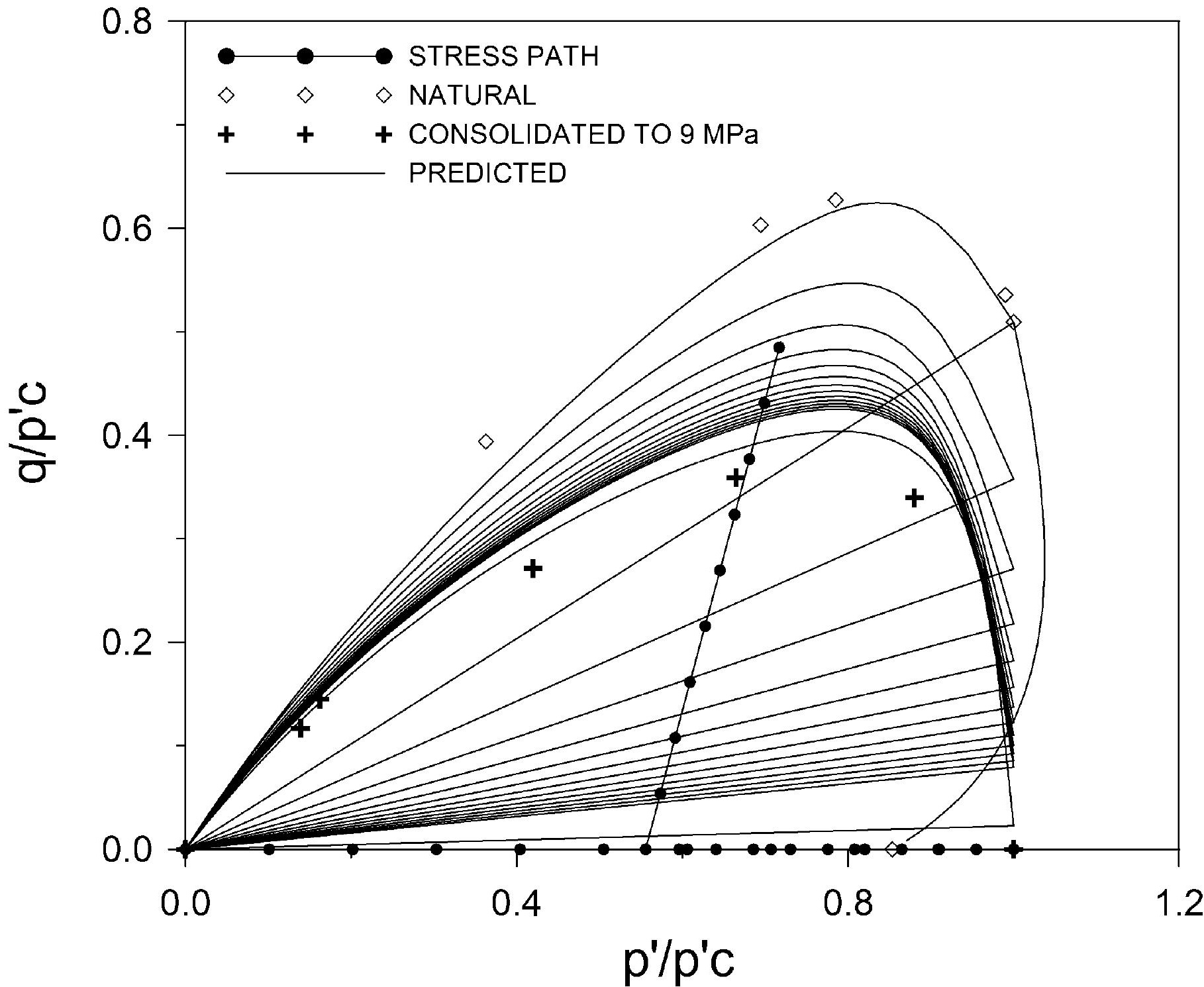




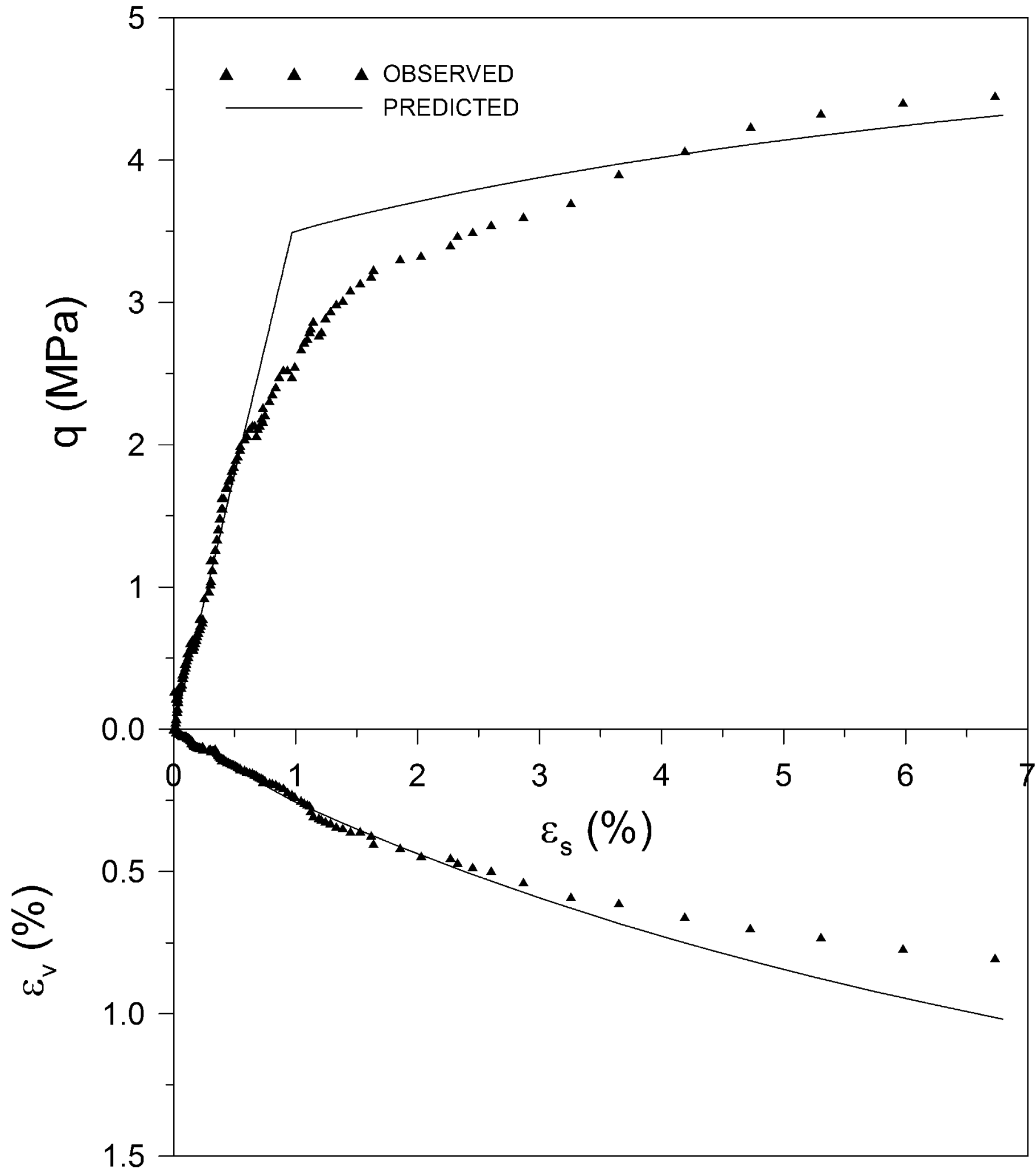




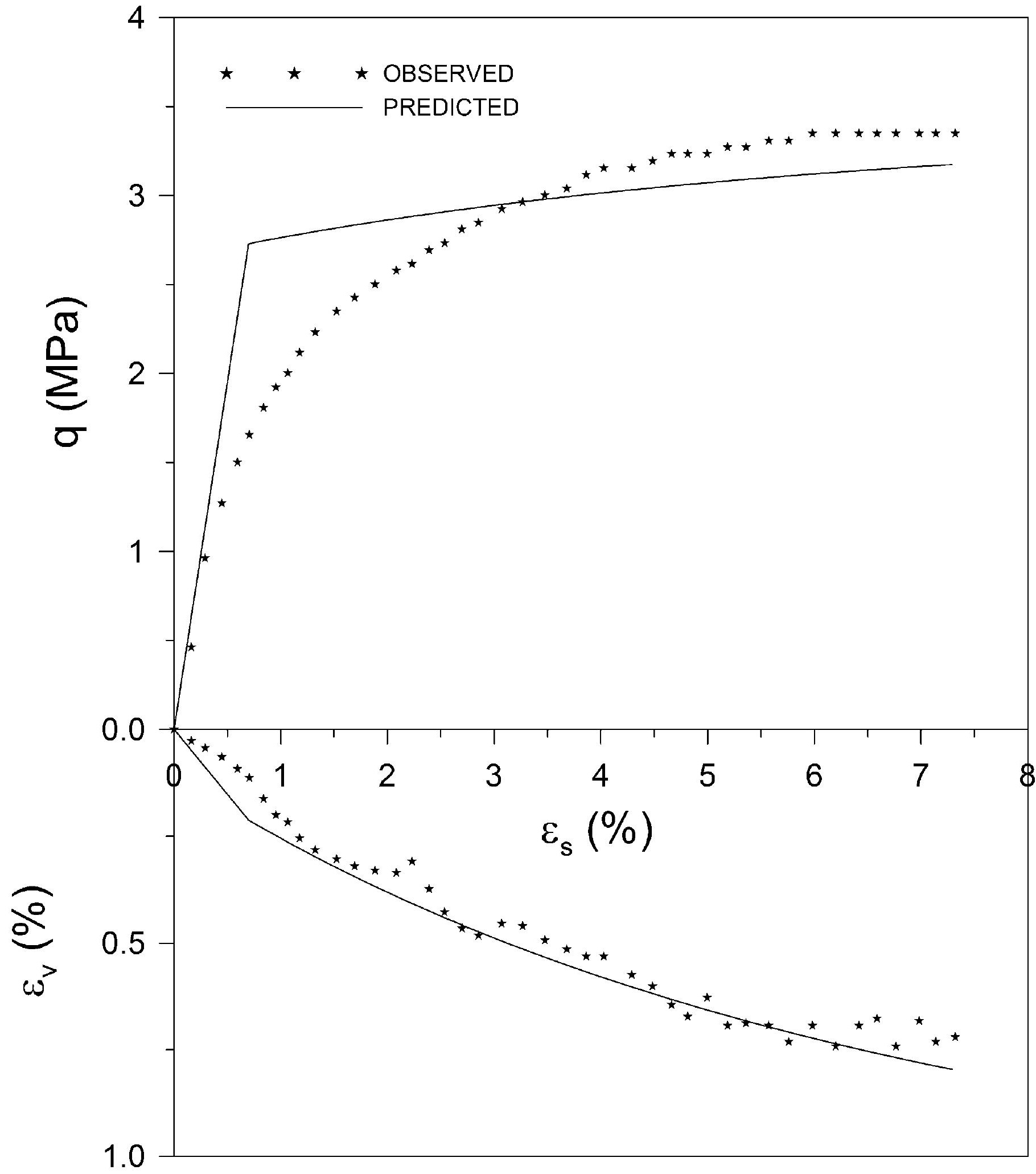




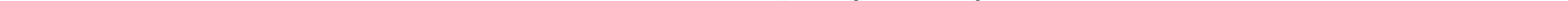

